\title{
ÉTICA, CLÍNICA E DIRETRIZES: A FORMAÇÃO DO PSICÓLOGO EM TEMPOS DE AVALIAÇÃO DE CURSOS ${ }^{1}$
}

\author{
João Leite Ferreira Neto \\ Lícia Mara Dias Penna"
}

\begin{abstract}
RESUMO. O presente artigo apresenta e discute os resultados de uma pesquisa sobre a relação entre ética e clínica no contexto da formação universitária do psicólogo. A clínica é entendida como um dispositivo ético de subjetivação, a partir da análise de conceitos extraídos de Lacan e Foucault. O trabalho de campo foi realizado numa instituição particular de ensino superior, com ênfase em sua clínica-escola. Os dados obtidos são colocados em um diálogo crítico com a proposta de Diretrizes Curriculares para os cursos de Psicologia. Salienta-se a importância da ética entendida como conjunto de "práticas de si" na formação geral do psicólogo, ainda que esta ênfase não seja contemplada pelas Diretrizes. Considera-se relevante que a dimensão ética da clínica "psi" esteja presente de modo transversal, não segmentado, na formação geral do psicólogo.
\end{abstract}

Palavras-chave: ética, psicologia clínica, formação do psicólogo.

\section{ETHICS, CLINIC, AND DIRECTIVES: PSYCHOLOGIST'S QUALIFICATION, IN TIMES OF COURSE ASSESSMENT}

\begin{abstract}
The current article presents and discusses the results of a research about the relation between Ethics and Clinic in the context of the university qualification granted to psychologists. Nowadays, Clinic can be understood as an ethical device of 'subjectivities', according to the analysis of concepts presented by Lacan and Foucault. Regarding fieldwork, the research was carried out in a private university, focusing its Clinic-school. Data were arranged in form of a critical dialogue with the proposal of the 'Curricular Directives for Psychology Courses'. The importance of Ethics, understood as a set of "self practices" is highlighted in the general qualification of psychologists, even if this emphasis is not considered by the Curriculum Directives. It is relevant that, the ethical dimension of "psy" Clinic might appear transversally, not segmented, in the general qualification of psychologists..
\end{abstract}

Key words: Ethics, clinic psychology, psychologist's qualification.

\section{ÉTICA, CLÍNICA Y DIRECTRICES: LA FORMACIÓN DEL PSICÓLOGO EN TIEMPOS DE EVALUACIÓN DE CURSOS}

RESUMEN. El presente artículo presenta y discute los resultados de una investigación sobre la relación entre ética y clínica en el contexto de la formación universitaria del psicólogo. La clínica es entendida como un dispositivo ético de subjetivación, a partir del análisis de conceptos extraídos de Lacan y Foucault. El trabajo de campo fue realizado en una institución privada de enseñanza superior, con énfasis en su clínica-escuela. Los datos obtenidos son puestos en un diálogo crítico con la propuesta de Directrices Curriculares para los cursos de Psicología. Se resalta la importancia de la ética entendida como conjunto de "prácticas de sî" en la formación general del psicólogo, aunque este énfasis no sea contemplado por las Directrices. Se considera relevante que la dimensión ética de la clínica "psi" esté presente de modo transversal, no segmentado, en la formación general del psicólogo.

Palabras-clave: ética, psicología clínica, formación del psicólogo.

\footnotetext{
1 Apoio: FUMEC e Fundação Nacional do Desenvolvimento do Ensino Superior Particular-FUNADESP.

* Doutor. Professor da pós-graduação da Pontifícia Universidade Católica de Minas Gerais-PUC-MG.

\# Mestre . Professora da Universidade FUMEC.
} 
O presente artigo apresenta os resultados de uma pesquisa iniciada em 2003 e concluída em 2004, tendo como objetivo geral a investigação entre ética e clínica no contexto atual da formação universitária do psicólogo. Esse objetivo geral se desdobrou em especificidades necessárias, que consistiram na apuração teórico-conceitual das noções de ética e clínica, para compreender sua intrínseca articulação, e na investigação empírica da formação em psicologia clínica através de um estudo de caso da clínica-escola de uma instituição privada de ensino superior. Buscamos também, nesse percurso, entender qual é lugar da clínica na formação geral do psicólogo. Com essa finalidade, os resultados obtidos foram postos em um diálogo crítico com a proposta das Diretrizes Curriculares veiculadas pelo Ministério da Educação, instrumento atual de avaliação e organizador dos novos currículos dos cursos de Psicologia.

Nosso primeiro passo consistiu, portanto, na localização de um campo teórico-conceitual que pudesse referenciar a associação entre clínica e ética. Nossa revisão bibliográfica indicou que o debate em torno da clínica tem se deslocado do campo da epistemologia para o da ética, na medida que a clínica passa a ser entendida, atualmente, menos como um modo de intervenção e mais como um dispositivo produtor de subjetividade - em suma, como um dispositivo ético de subjetivação. O resultado desse estudo foi publicado na forma de artigo no periódico Psico (Ferreira Neto \& Penna, 2004), e com base nele faremos uma breve síntese para permitir uma melhor leitura do material inédito aqui apresentado.

Rolnik (1995) afirma que as práticas clínicas participam, direta ou indiretamente, da composição dos territórios subjetivos; Figueiredo (1995), que as diferentes teorias e técnicas clínicas constituem-se como dispositivos que interferem na constituição e na formação dos homens e conseqüentemente de seus mundos. Os autores apontam que cada teoria e cada técnica no campo da psicologia tornam-se uma operação ética, criando e produzindo subjetivações o que justifica a relevância do estudo desta relação, e em especial, o modo como se dá a transmissão da perspectiva ética na formação do psicólogo.

Encontramos, particularmente nas obras de Lacan e Foucault, elementos que nos permitiram desvelar a associação entre ética e clínica. Contrariamente à acepção hegemônica que entende a ética como uma "reflexão" sobre os princípios morais (Japiassu \& Marcondes, 1990, p 90), numa perspectiva universal, Lacan e Foucault buscam compreender a ética na contemporaneidade interrogando a singularidade da subjetivação, a responsabilidade do sujeito e suas possibilidades de auto-invenção.

Foucault discorreu sobre o fato de todo sistema moral possuir um conjunto de "práticas de si" a ele associado, práticas através das quais o indivíduo se constitui a si mesmo como sujeito ético. No contemporâneo a clínica psicológica pode ser considerada como um dispositivo de subjetivação, portador de uma dimensão ética.

Não existe conduta moral que não implique a constituição de si mesmo como sujeito moral; nem tampouco constituição do sujeito moral sem 'modos de subjetivação', sem uma 'ascética' ou sem 'práticas de si' que as apóiem (Foucault, 1984, p. 28).

A clínica $p s i$, para Foucault, apresenta-se como um campo onde se dá tanto aplicação de técnicas disciplinares que visam a uma auto-realização normalizadora quanto uma "experiência" em que se intensificam processos singulares de subjetivação.

Lacan foi o primeiro autor do campo "psi" a teorizar sobre a aproximação necessária entre ética e clínica, afirmando que a experiência psicanalítica é, antes de tudo, uma experiência ética. "Os limites éticos da análise coincidem com os limites de sua práxis" (Lacan, 1988, p. 32). Lacan privilegia como princípio da ética a relação singular do sujeito com o desejo. A clínica é entendida como uma experiência que leva o sujeito ao confronto radical com o que o constitui e a se responsabilizar por esta dimensão, que causa sua ação, seu modo de estar no mundo.

Ressalvadas as diferenças entre os autores, ambos concordam que a noção de um homem universal, portador de uma essência que permita uma legislação consensual ou a possibilidade de uma ética universal, não se sustenta, o que exige uma constante reflexão sobre qualquer ação que incida sobre o sujeito e sua singularidade, o que inclui o manejo da ação clínica (Badiou, 1995 \& Rajchman, 1993).

\section{MÉTODO}

Seguimos as indicações metodológicas preconizadas por Foucault em sua arqueogenealogia, desenvolvendo a pesquisa numa perspectiva problematizante. Para Foucault citado por Ferreira (2004), a problematização envolve o reconhecimento de elementos que se apresentam como problema e forçam ao exercício do pensamento no tempo presente. Isso implica no entendimento da ética e da clínica como questões que não são evidentes em si mesmas. A pesquisa construiu assim 
um plano conceitual e um domínio empírico, uma vez que essas noções estão aqui sendo entendidas como práticas, conjuntos de modos de fazer, que devem ser problematizados e investigados.

Utilizamos três fontes de dados. Primeiramente, aplicamos um questionário, contendo três questões abertas, aos alunos do segundo e décimo períodos do curso de psicologia dessa universidade. Agrupamos as diferentes respostas em categorias maiores, duas ou três em cada caso, separando os dados entre os segundos períodos e os décimos períodos, de modo a permitir a análise dos efeitos da formação nas concepções de alunos de início e final de curso.

$\mathrm{Na}$ seqüência, realizamos com seis de oito professores-supervisores uma entrevista semidirigida, contendo seis perguntas acerca da forma como eles compreendem e transmitem a relação entre ética e clínica. Fizemos uma análise de conteúdo acompanhando as indicações de Turato (2003), iniciando por "leituras flutuantes" do material coletado, de modo a permitir uma impregnação dos conteúdos, preparando assim o processo de análise. A análise seguiu dois critérios importantes: o da repetição e o da relevância dos elementos presentes nas falas dos entrevistados.

Optamos, também, pela realização de uma entrevista coletiva, utilizando o mesmo roteiro, com alunos-supervisandos indicados pelos supervisores, a qual foi analisada pelos mesmos critérios utilizados nas entrevistas com os supervisores, ainda que, como mostraremos na seqüência, esse instrumento "entrevista coletiva" tenha promovido movimentos diversos daqueles promovidos pelo instrumento "entrevista individual". Todas as entrevistas foram gravadas e transcritas. Os supervisores foram numerados e indicados pela letra "P", enquanto os alunos foram também numerados e indicados pela letra "A".

Para finalizar, estabelecemos uma discussão da análise dos dados recolhidos destas fontes com a proposta das Diretrizes Curriculares para o curso de Psicologia. Esse procedimento permitiu problematizar melhor o momento atual da formação universitária em Psicologia no Brasil, além de propor uma leitura crítica, sob o recorte do tema pesquisado, da proposta de Diretrizes Curriculares.

\section{RESULTADOS}

\section{Falam os alunos}

Inicialmente, quando interrogados acerca da ética na psicologia clínica, $43,5 \%$ dos alunos dos $2^{\text {os }}$ períodos articularam essa noção ao Código de Ética Profissional, enquanto $47,5 \%$ a relacionaram com a construção de uma postura profissional apresentada, por exemplo, nas seguintes respostas: "saber ouvir, analisar e intervir”, "construir uma relação confortável e honesta com o cliente", "ter bom senso e responsabilidade, dedicação e comprometimento", ou com atitudes subjetivas a serem desenvolvidas, tais como "respeito às próprias limitações", "separar seus próprios problemas e valores dos problemas do paciente", "respeito ao paciente, ao colega de profissão", "humildade para reconhecer limites". No que se refere aos $10^{\text {os }}$ períodos, a ênfase dada às posturas e às atitudes aumentou para $72 \%$, enquanto apenas $22 \%$ das respostas associam a ética ao Código Profissional. Cabe salientar que, entre as respostas apresentadas pelos alunos de $10^{\text {os }}$ períodos, apareceu uma estreita ligação entre a ética e os cuidados com a própria formação. Os alunos falam da importância da "preparação do profissional”, "da necessidade de se dominar a abordagem escolhida"; ressaltam o valor da "atualização continuada, teórica e pessoal" $e$ "da preparação e capacitação intelectual”; ou seja, entendem a indissociabilidade entre a formação e a ética.

$\mathrm{Na}$ segunda questão, que dizia respeito à forma de transmissão da ética no curso de Psicologia, 56\% dos alunos $\operatorname{dos} 2^{\text {os }}$ períodos atribuíram às atividades de ensino em geral ("disciplinas específicas", "aula sobre legislação e ética", "estudos de caso" "palestras" e "seminários") o encargo dessa transmissão. 31,5\% acreditam que a noção de ética é transmitida através de estudos teóricos, e $12 \%$ acreditam na transmissão através de atividades práticas, tais como "vivências", "exemplos de situações de atendimento", "relatos do dia-a-dia de um bom profissional", etc.

Nos $10^{\text {os }}$ períodos ocorre uma diferença de ênfase: os estudos teóricos (46\%) são sobrevalorizados em detrimento das atividades de ensino tomadas em geral (29\%). Em relação aos alunos de $2^{\circ}$ período, nos $10^{\circ}$ períodos sobe a porcentagem dos que acreditam na transmissão da ética através de atividades práticas (24\%).

Finalmente, quando se lhes perguntou quanto ao modo de se demonstrar a ética na formação clínica, $49 \%$ dos alunos de $2^{\circ} \mathrm{s}$ períodos apontam para as atitudes para com os pacientes e os colegas de profissão ("respeito aos próprios limites", "respeito com o paciente"), 40,5\% para o respeito ao código de ética profissional e 5\% para uma formação continuada, que envolve a continuação de estudos e psicoterapia pessoal. 
Nos $10^{\text {os }}$ períodos as atitudes são mais valorizadas. $61 \%$ dos alunos apontam para essa direção, com respostas tais como: "respeito ao paciente", "respeito aos próprios limites", "comprometimento com a clínica", "coerência com a abordagem escolhida", etc. $13 \%$ valorizam a formação continuada nesse aspecto: "aprimoramento da formação", "estudos de pós-graduação" "questionamento da própria prática"; e apenas 11,5\% se referem ao Código.

Em síntese, quando comparamos as respostas dos alunos de $2^{\text {os }}$ e $10^{\text {os }}$ períodos, pudemos constatar que ao longo do curso os alunos vão se sensibilizando para a importância da ética. Esta se apresenta cada vez mais ligada a uma formação continuada, tanto nas atividades de sala de aula, quanto nas atividades práticas fora de sala de aula - a psicoterapia pessoal, a supervisão, etc. - onde se desenvolve, além de um aperfeiçoamento técnico-profissional, o exercício de uma postura ética que baliza o fazer no campo da clínica.

\section{Falam os supervisores}

Com relação à importância da ética na formação do psicólogo, os professores-supervisores foram unânimes em reconhecer a importância da ética na formação, considerando que ela é o que "move a prática clínica". A ética é considerada tão fundamental na prática do psicólogo que chega a ser tomada como mais importante do que a própria dimensão técnica. Alguns professores salientam que, na verdade, é a postura ética que leva os psicólogos a buscar subsídios técnicos e uma apropriação cada vez maior de saber (P3).

Partindo desta importância, os supervisores se detiveram numa explicitação do conceito de ética. Alguns partiram do pressuposto de uma Ética Geral, ligada ao Código de Ética Profissional, que propõe o "sigilo, o respeito ao paciente e a formação minimamente completada" (P2) como pré-requisitos formais para a atuação clínica. No entanto, outros supervisores se referem a uma noção de ética mais específica, ligada à proposta clínica de cada abordagem. O "imperativo" ético psicanalítico, que se refere ao dito lacaniano "O sujeito não deve ceder de seu desejo", foi evocado pelos supervisores de psicanálise; a expressão "comportamento ético" foi usada pelo supervisor da análise comportamental; e a ética como "uma forma de presença junto ao outro" foi proposta pelo supervisor da terapia centrada. Podemos destacar a fala de um dos supervisores em que a concepção de uma ética particular, vinculada a uma determinada abordagem do campo psicológico, é descrita com clareza:

"Cada abordagem tem uma ética, pois cada
uma tem uma concepção de sujeito e uma
concepção do que deve ser a intervenção.
Acho que uma teoria orienta uma ética sim e
quando podemos conhecer alguma coisa do
trabalho de um terapeuta, podemos apreender
a posição ética implicada em sua abordagem"
(P1).

Neste caso, a ética é entendida como vinculada aos pressupostos fundamentais de cada abordagem, orientando, assim, a ação do psicólogo. Mesmo não sendo esta uma posição unânime, pois alguns professores afirmam existir apenas uma Ética Geral (P5) e (P6), todos concordam que a transmissão da ética implica levar em consideração a singularidade de cada situação clínica, a especificidade de cada caso.

Quando indagados sobre as questões que os alunos costumam levantar na supervisão, os supervisores apontam que a maioria delas gira em torno do que se deve ou não dizer, do que se deve ou não fazer, demonstrando uma demanda relativa a prescrições de conduta. De acordo com os supervisores, os alunos perguntam:

\footnotetext{
"se deve ou não citar o nome do paciente; se pode atender um paciente que é filho do amigo; se é ético fazer algum tipo de crítica para a mãe da criança que está sendo atendida, etc." (P3); "como fazer as intervenções, quando silenciar (P4)".

"Tem horas que os alunos querem saber quanto se cobra, o tempo, a duração, o limite, a população que procura (P5)".
}

No entanto, embora essas questões possam ser entendidas como busca de orientações unicamente técnicas, vários supervisores entendem que elas contêm em si o cerne da dimensão ética implicada na prática clínica. Um dos supervisores destaca o fundamento ético dessas perguntas dizendo: "Eles não têm muita clareza, às vezes, de que essas são questões éticas, muito mais do que técnicas" (P3).

$\mathrm{Na}$ verdade, as demandas dos alunos trazem implícita sua dificuldade em "ocupar o lugar de não saber, que é uma posição ética difícil de sustentar" (P1), pois o saber teórico não recobre àquilo que o real da experiência apresenta, apontando sempre para uma conduta ética que requer a escuta da particularidade de cada caso (Penna, 2003). Fica claro na fala da maioria dos supervisores que não existem respostas prontas, 
padrões de conduta normativa. Neste sentido, a solução apontada por um dos supervisores merece ser destacada por sua relevância: segundo ele, é preciso "construir um certo vetor da escuta para que o próprio aluno encontre o tempo de dizer" (P1), ou o modo de fazer.

Existe um reconhecimento unânime da importância do processo psicoterapêutico do aluno envolvido com a condução de um caso clínico, tal como indica a seguinte fala: "o sujeito deve se haver com as próprias questões para que ele consiga desimpedir um pouco o caminho do outro"; há uma dimensão da "transmissão da clínica que é feita no próprio tratamento..." (P3). Contudo, alguns reconhecem que a psicoterapia pessoal, por si só, não é garantia da habilidade de condução de um tratamento: "Nada garante que quem tem dois anos de análise vai atender melhor do que quem tem menos" (P1). Em contrapartida, alguns alunos que ainda não estão em psicoterapia pessoal demonstram habilidades na condução dos casos em atendimento, por demonstrarem certa "sensibilidade". "Às vezes você vê que o sujeito é sensível, sensível às próprias questões e que ele, por uma circunstância, não pode estar se tratando..." (P3).

Podemos entender, destarte, que a formação na clínica envolve muito mais que a assimilação de conteúdos teóricos e técnicos, mas passa por um conjunto de procedimentos onde a psicoterapia pessoal é um elemento-chave, mas não o único. Além da indicação ou sugestão para que os alunos se submetam à psicoterapia, outros procedimentos são adotados na supervisão na tentativa de transmissão da ética. Um deles é a leitura de artigos sobre a técnica e de casos da literatura especializada, nos quais se podem salientar e destacar os problemas éticos (P1). Outro procedimento é ressaltar a dimensão ética nas situações cotidianas da clínica, tais como a forma de oferecer acolhimento ao paciente e a suspensão do julgamento moral (P3). Na tentativa de sanar "o abismo que se abre entre a compreensão dos conceitos e sua colocação em prática", vale ressaltar que um dos supervisores (P6) propõe um role-playing onde é simulada a situação de atendimento, que é gravada e posteriormente analisada. Um aspecto relevante da supervisão diz respeito ao manejo da insegurança e angústia geradas nos alunos por situações de atendimento (P1) e (P4), o que torna a própria situação da supervisão um destes procedimentos. "Então, todas as dificuldades, as angústias vão sendo discutidas, e essa questão [a ética] sempre aparece". Algumas falas ilustram aspectos relativos a essa questão:
"Essa transmissão vai sendo feita na medida mesmo em que o sujeito vai aprendendo a lidar com a situação clínica. É preciso insistir mais na questão ética do que na questão técnica" (P3).

"É quando a prática acontece que dá para a gente discutir..." (P5).

"A ética do desejo acaba por se revelar como diretamente associada ao modo como o supervisando deve estar atento a ter respeito pelo sujeito e por aquilo que de mais particular o sujeito pode trazer (P2)".

Podemos concluir que a formação clínica acarreta a constituição de um campo de experiência que não pode ser reduzido à prescrição pedagógica presente na relação tradicional entre professor e aluno. Ela implica uma prática que não se restringe à observação ou à demonstração, mas que tem conseqüências tanto no aluno quanto no "paciente" por ele atendido. Ou seja, a formação, assim entendida, constitui-se numa prática que promove processos de subjetivação.

\section{Falam os supervisandos}

A entrevista coletiva com os alunos mostrou-se uma técnica fecunda de coleta de dados. Apresentamos aos seis alunos presentes o mesmo roteiro da entrevista feita com os professores-supervisores. Entretanto, na entrevista coletiva o efeito não foi o mesmo obtido nas entrevistas individuais. $\mathrm{Na}$ entrevista coletiva, a pergunta apenas desencadeava um processo no qual uma resposta podia promover um redirecionamento para as falas seguintes. Em alguns momentos, a discussão desenvolvida negligenciava por completo a direção inicial proposta na pergunta, ficando capturada por um tema que emergia de uma das falas. O exemplo mais acabado disso ocorreu na pergunta três, quando os supervisandos foram indagados quanto ao tipo de questões sobre a ética que costumavam levantar durante as supervisões. Um aluno citou o exemplo das dificuldades no atendimento dos casos de psicose. $\mathrm{O}$ que aconteceu em seguida é que o tema "psicose" tornou-se o centro das discussões, negligenciando-se assim a direção inicial da pergunta. O tema da psicose apresentou-se como emergente privilegiado, em torno do qual os supervisandos podiam abordar uma série de inquietações provenientes do fazer clínico. Por essa razão, catalisou, em vários momentos, o foco do debate do grupo.

Um segundo aspecto curioso surgido durante o uso da técnica de entrevista coletiva foi o efeito de 
alguns "fenômenos de grupo" influenciando o conteúdo das respostas - nesse caso, um fenômeno de "transferência lateral", uma transferência que se estabelece entre os pares membros do mesmo grupo (Zimerman \& Osório, 1997). Na questão quatro do roteiro, quando se inquiriu se cada abordagem clínica tem uma perspectiva ética ou se existe uma ética comum a todas as abordagens, ocorreu a primeira discordância direta entre os supervisandos. Isso desencadeou um processo no qual todos os supervisandos de psicanálise aderiram em bloco, solidariamente, ao mesmo ponto de vista do primeiro que discordou da posição de um colega que fazia supervisão em outra abordagem. Contrariamente às expectativas, esses alunos defenderam a não-existência de uma ética particular por abordagem, posição contrária à de seus supervisores psicanalistas. Vale lembrar que Lacan desenvolveu todo um seminário sobre a ética, particular, da Psicanálise.

Finalmente, percebemos que, em geral, as respostas foram tomando a forma de uma elaboração coletiva dos temas. Acompanhamos, ao longo da entrevista, uma construção coletiva de idéias na qual os alunos elaboravam não estritamente o que era perguntado, mas o que se apresentava a eles como o mais interessante ou inquietante.

No início da entrevista, a primeira resposta apresentada pelos alunos com relação à importância da ética fazia referência aos filósofos gregos, com as expressões "conhecer a si mesmo" e "cuidar de si". Esta dupla noção foi embasando toda a discussão até desembocar numa distinção entre a formação teórica e a formação pessoal, que foram consideradas por todos como os dois pilares da formação clínica.

"É uma questão que é pessoal e outra que vai ao nível da teoria mesmo" (A1).

“... às vezes a gente pode pensar que basta $o$ cuidar de si para atender e na verdade a gente tem que estar embasado numa teoria mesmo" (A5).

Esta complementaridade entre formação teórica e formação pessoal foi ressaltada ao longo de toda a entrevista. Os alunos compreendem que a dimensão ética do "cuidar de si" inclui o processo de psicoterapia pessoal, determinante na condução do caso clínico. A clínica é um espaço de relação diferenciado que requer um desvelo por parte do terapeuta em sua conduta. A fala do terapeuta tem aí uma função e um peso significativos, e sua intervenção exige precisão, já que envolve certos riscos. Os alunos se mostram preocupados com a possibilidade de que questões pessoais podem interferir negativamente no trabalho, daí a importância do processo psicoterapêutico pessoal. Eles entendem a importância da psicoterapia entendida como "cuidado de si" de modo a evitar confundir-se com o outro, risco que constantemente ronda a prática clínica.

"O que a gente fala tem um peso para o paciente que é diferente da fala para um colega [...] a questão da ética e do cuidado de si e do conhecer-se a si próprio, é importante para a gente ter claro o que são questões nossas que podem interferir, que podem atrapalhar o trabalho. Tem que ter muito cuidado" (A2).

"Eu acho isso muito importante porque às vezes a gente se pega querendo que o cliente faça uma coisa que não está na realidade dele. Eu acho interessante essa preocupação que ele [o supervisor] tem com isso aí, que implica mesmo esse cuidado, não querer impor a ele [o paciente] os nossos valores, a nossa visão de mundo..." (A2).

"É um trabalho muito delicado, que tem um comprometimento muito sério com relação ao sujeito, seja o encaminhamento, seja o tratamento, seja a intervenção que você faz errada. Você está lidando com um sujeito ali que te coloca num lugar especial, lugar do saber. Então eu penso que para atender é fundamental [a psicoterapia]" (A5).

A discussão em torno da importância da formação teórica evidenciou, entre os supervisandos, a exigência de fidelidade à teoria e, conseqüentemente, um combate ao ecletismo. "E o que não seria ético, seria essa mistura, esse ecletismo, que, afinal de contas, você vai se perder por ẩ' (A3).

Certas falas são recorrentes e atravessam o debate entre os supervisandos. Várias delas dizem respeito ao fato de não existir um regramento a priori do que se deva fazer, do que se deva dizer na situação clínica. Entretanto, a relação dos alunos com este fato é paradoxal. Por um lado, há uma insistência reiterada na afirmação de que "cada caso é um caso", "não há garantias.":

"Quem vai para a supervisão atrás dessas respostas se frustra muito, porque cada atendimento é único... e se a pessoa se apega ao que é dito pelo supervisor, ela não consegue andar por si só” (A5).

Por outro lado, há um discreto lamento pela nãoexistência de respostas-padrão. "Ela não dá respostas 
e isso angustia algumas pessoas, porque nós, alunos, muitas vezes estamos atrás disso, de muitas respostas" (A5). Os supervisandos se inquietam com o fato de saberem não existirem respostas prévias ante a diversidade das situações clínicas.

A questão relativa à psicose surgiu como um exemplo de uma situação delicada que mobilizou os supervisandos. Por essa razão, tomou grande parte do tempo do debate, realçando a importância da escuta singular de cada sujeito e da construção do manejo clínico que cada caso requer.

"Eu estou atendendo um caso de psicose; a todo momento que eu penso em dizer alguma coisa eu tenho todo um cuidado do que deve ser dito, devido à delicadeza desse caso em especial $[\ldots]$ eu acho que a gente faz uma aposta ali na hora da intervenção" (A5).

É importante ressaltar como os alunos vão construindo, coletivamente, uma compreensão do que vem a ser a clínica em psicologia articulada à noção de ética. Clínica e ética, neste campo, são entendidas como dimensões que se entrelaçam. $\mathrm{O}$ ponto mais alto desta elaboração aparece no final da entrevista. Os supervisandos discutem o manejo da relação com os pacientes apontando, de um lado, a importância do lugar do terapeuta, e de outro, os riscos de se superestimar a própria importância. "A gente tem mesmo essa tendência de segurar o paciente” (A2) "Achar que ele não pode viver sem você" (A5). Tudo isso afeta o desenvolvimento do tratamento e exige atenção constante consigo mesmo e com a relação terapêutica. "Às vezes a gente torce tanto por um paciente que acaba atrapalhando um tratamento" (A6).

A noção de clínica que transpareceu no decorrer da entrevista é que esta é um lugar que provoca angústia, na medida em que não há neutralidade possível: o terapeuta participa dessa atividade com sua pessoa. O que ele diz tem uma importância sensível para o paciente e ambos são afetados por essa experiência. Daí a importância ética do cuidado, na medida em que nesta prática ele é afetado, "comovido", sem, no entanto, poder confundir suas próprias questões e vivências com as que o paciente lhe traz. A clínica foi discutida como uma experiência que produz, ao mesmo tempo, certo nível de mistura e um necessário movimento de distinção entre o que é de si próprio e o que é do outro. Aí se apresenta o cerne e a grande dificuldade dessa prática. Vale salientar que essa essencial e problemática dimensão da clínica, comumente abordada por diversas teorias através de conceitos tais como "transferência" ou "empatia", surgiu com clareza na discussão entre os supervisandos, marcada por um frescor próprio de iniciantes entusiastas, que, no entanto, ainda não se armaram de um arsenal teórico-conceitual mais amplo para se haverem com essa prática.

\section{DISCUSSÃO}

No parecer da relatora, Silke Weber (Brasil, 2002), a proposta das Diretrizes Curriculares é apresentada como promotora da substituição de "uma tradição curricular caracterizada pela enunciação de disciplinas e conteúdos programáticos por diretrizes curriculares baseadas em competências e habilidades profissionais". Por conseguinte, a proposta abandona uma compreensão da formação entendida como assimilação de conteúdos de conhecimento, em favor de uma perspectiva da formação entendida como desenvolvimento de competências e habilidades. Desta forma, podemos entender, com base no que desenvolvemos na investigação, que a proposta toma a formação como um processo de subjetivação, na medida em que o produto final não é puramente cognitivo de transmissão de informações, mas visa a uma transformação dos indivíduos implicados nesse processo.

Não obstante, essa perspectiva assumida não é problematizada dessa maneira no corpo do texto. Encontramos aí apenas a descrição dos princípios gerais, dos perfis, das competências e habilidades, dos conteúdos curriculares, da organização do curso e dos estágios e atividades complementares (Brasil, 2001). Ou seja, trata-se de descrever a produção das subjetividades almejadas, e não de problematizar o currículo como veículo de produção de processos de subjetivação.

$\mathrm{Na}$ busca de sua menção em nosso tema, encontramos a palavra ética em apenas duas ocasiões. A primeira, nos "Princípios Gerais", item $e$, com o seguinte enunciado: "Respeito à ética nas relações com clientes e usuários, com colegas, com o público e na produção e divulgação de pesquisas”. O que aparece, portanto, é uma concepção de "ética profissional", fundamentada numa deontologia e com claras referências às exigências do Código de Ética. A segunda vez, encontramo-la nas "Competências Gerais", no âmbito da saúde, como exigência de uma atuação "dentro dos mais altos padrões de qualidade e dos princípios da ética/bioética". Mais uma vez, a ética aparece associada a um código de princípios.

A ênfase das Diretrizes recai na importância a ser concedida ao "desenvolvimento científico da Psicologia, no reconhecimento da atual diversidade 
dos contextos de atuação" profissional e à preocupação com o "exercício da cidadania". Essas são as três linhas-mestras que organizam o texto das Diretrizes Curriculares. Se em relação aos novos contextos de atuação as referências são claras, o modelo de ciência em questão possui referências paradoxais. Por um lado, nos Conteúdos Curriculares fala-se em "fundamentos epistemológicos" e, na seqüência, em "fundamentos metodológicos", sempre no plural; por outro, nas habilidades, item $c$, lê-se: "Utilizar os métodos experimental, de observação e outros métodos de investigação científica". Mesmo com a indicação para uma pluralidade no âmbito da epistemologia e da metodologia, o modelo de investigação das Ciências Naturais possui aqui um evidente privilégio. A grande contribuição da Psicologia para as metodologias de pesquisas qualitativas, a pesquisa-ação, não é sequer mencionada, mas apenas os métodos "experimental" e "de observação." Pode-se supor que este privilégio dado a essa perspectiva de Ciência contribui para que os parâmetros curriculares não sejam descritos como um dispositivo de produção de processos de subjetivação. Para as Ciências Naturais, a subjetividade do psicólogo-pesquisador deve-se apagar diante do rigor metodológico. Com isso esvazia-se a importância da contribuição que a clínica pode trazer para a formação geral do psicólogo, dissociando a prática clínica do núcleo essencial da formação.

Em nossa pesquisa, percebemos a noção da ética como componente necessário, não contingente, da formação do psicólogo. A presença da clínica nesta formação implica em "práticas de si" como prérequisito para a atuação do psicólogo. Contudo, essa contribuição da clínica não foi incorporada pela proposta de Diretrizes Curriculares. Nelas, prevalece a imagem do psicólogo cientista e cidadão, portador de competências e habilidades, mas sem a referência necessária ao trabalho ético sobre si que sua formação exigiria. Se no passado recente houve uma supervalorização da área clínica, em detrimento de outras áreas de atuação importantes para o psicólogo, percebemos no presente uma negligência com relação às importantes contribuições da clínica na formação geral. Encontramos assim, dentre as nove competências básicas e as sete habilidades requeridas na formação do psicólogo, apenas uma que aborda esta questão, e, mesmo assim, de modo tangencial: a competência $h-$ "relacionar-se com o outro de modo a propiciar o desenvolvimento de vínculos interpessoais requeridos na sua atuação profissional". No restante dos itens das competências e habilidades, encontramos uma descrição restrita a uma perspectiva eminentemente instrumental - "Identificar e analisar (...) escolher e utilizar instrumentos e procedimentos de coletas de dados (...) avaliar problemas (...) levantar informação (...) planejar (...) analisar, descrever e interpretar (...) utilizar recursos da matemática, da estatística e da informática (...)". Mesmo no quesito Estágios e Atividades Complementares, as Diretrizes também não avançam, limitando-se a remeter seus objetivos a garantir o "desenvolvimento das competências" específicas e exigir a instalação de um serviço de Psicologia.

Essa ênfase nas "práticas de si" como componente ético importante da formação aparece nas entrevistas de todos os supervisores, inclusive, para citar a abordagem epistemologicamente mais distante da psicanálise, na entrevista com a supervisora de terapia comportamental. Parece-nos ainda que essa ênfase, mesmo tendo origem nas abordagens psicanalíticas e existencial-humanistas sob a forma, às vezes restrita, da exigência de uma psicoterapia pessoal a ser feita pelo formando, atualmente, permeia toda a formação em Psicologia. Desafortunadamente, esse fator não foi reconhecido pela proposta das Diretrizes ${ }^{2}$.

\section{CONCLUSÃO}

$\mathrm{Na}$ presente tendência de reformulações de currículo provocada pelas Avaliações Nacionais de Cursos, um debate tem sido constante: a área clínica estava inflacionada na maior parte dos currículos. Desde a regulamentação da Psicologia como profissão, em 1962, a área clínica se configurou como sendo a mais destacada, a mais procurada e a mais valorizada, tendo grande influência na construção da imagem social do psicólogo. Esta marca da área

2 Em 07/05/2004, após a conclusão de nossa pesquisa, foi aprovada a versão definitiva do relatório sobre as Diretrizes Curriculares, com uma nova redação elaborada pela profa. Marília Ancona-Lopez (Brasil, 2004). Contudo, a forma final não alterou a ausência de um enfoque da ética como experimentação subjetiva, como conjunto de "práticas de si", a ser tomado como elemento importante na formação do psicólogo. Há que se notar o acréscimo da possibilidade de uma ênfase em Psicologia $e$ processos clínicos, onde se reconhece a relação entre ética e prática clínica. Fica, no entanto, restrita a uma possível ênfase a ser oferecida, entre as seis sugeridas pelo documento, sem o desenvolvimento de uma problematização mais ampla da contribuição da clínica no contexto global da formação. 
clínica provocou uma identificação generalizada do profissional psicólogo com a função de um psicoterapeuta (Ferreira Neto, 2004). Isto acarretou a tendência de se elevar o número de disciplinas da área clínica oferecidas nos currículos "antigos". Esta distorção tem sido um dos temas-chave dos novos projetos curriculares. Contudo, mesmo considerando importante uma redução da carga das disciplinas da área clínica nos currículos, percebemos que essa medida não é suficiente, pois atinge, de fato, apenas um problema secundário. $\mathrm{O}$ excesso do número de disciplinas voltadas para a clínica era, em nosso ponto de vista, acompanhado por um outro problema de maior relevância: a área clínica funcionava e, infelizmente, ainda funciona, fechada em torno de si mesma, sem interlocução com o restante do curso. $\mathrm{Na}$ pesquisa ela se apresenta essencialmente localizada no espaço clínica-escola-estágio: aí ela é discutida, implementada e desenvolvida. No restante do curso sua importância é, ao mesmo tempo, reconhecida e ignorada. Portanto, sua contribuição na formação do psicólogo se dava, e ainda se dá, de forma compartimentalizada.

Como demonstrou a presente pesquisa, o essencial da contribuição da clínica, sua dimensão ética entendida como um conjunto de procedimentos semelhantes a uma ascese moderna, ainda que realçada na perspectiva dos professores e dos alunos, é, em geral, ignorada nas organizações formais dos currículos. Não podemos afirmar que ela comparece como parte do chamado "currículo oculto", da Psicologia, na medida em que sua importância é conscientemente reconhecida pelos professores e alunos. Trata-se, na verdade, de uma formação explicitamente valorizada por formadores e formandos, mas ausente do currículo formal e, conforme constatamos, também da proposta das Diretrizes Curriculares.

Curiosamente, essa "habilidade" clínica (novamente lembramos: mais ética que técnica) é esperada de todo psicólogo, mesmo quando este atua fora da área estritamente clínica. Espera-se do psicólogo, seja na Educação, seja na Organização ou em outra área de atuação qualquer, certa "sensibilidade" ou capacidade de "escuta" que, em geral, é enfatizada na formação clínica. Em suma, a sociedade espera do psicólogo, em qualquer área em que este trabalhe, uma "habilidade" clínica, mesmo quando a prática de psicoterapia esteja distante das

Tomás da Silva define "currículo oculto" como aspectos do ambiente escolar que, sem fazer parte do currículo explícito, contribuem, de forma implícita, para aprendizagens sociais relevantes (Silva, 2002, p. 78). funções que ele exerce naquele contexto. Isso realça a necessidade de que a dimensão ética da clínica "psi" deva estar presente de modo transversal, não segmentado, tanto nos currículos quanto nas Diretrizes Curriculares propostas pelo Ministério da Educação.

A que fatores poderíamos atribuir este silêncio oficial acerca desta fundamental faceta da formação do psicólogo? Esta pergunta extrapola o escopo da pesquisa que realizamos e, indubitavelmente, abre espaço para novas investigações. Mesmo assim, podemos apresentar uma hipótese inicial. Parece-nos que se trata de uma dificuldade que, em parte, decorre daquilo mesmo que caracteriza a ética no campo da clínica. A ética tomada como conjunto de "práticas de si” possui como matéria-prima o "invisível", parte integrante e constituinte de toda realidade, camada intensiva que atravessa as palavras e as coisas.

Eu diria que é nessa esfera do invisível que se passa o essencial, que aí está a matéria prima da clínica, onde as virtualidades estão presentes num estado de oferecimento, à espera de enganches, atualizações, proliferações (...), a partir da qual certos processos de subjetivação podem desdobrar-se e ganhar consistência (Pelbart, 1992, p. 8).

A definição do "como" dessa formação, que tem como elemento fundamental o invisível, pode trazer algumas marcações no regime das "visibilidades" do currículo, mas ainda é tarefa por se realizar. Falamos em "algumas marcações", assumindo a posição de que a relação do invisível com o regime de visibilidades formais não implica sua plena iluminação, entendendo que a atmosfera própria da clínica é crepuscular, refratária ao sol de meio-dia. Os professores e estudantes, a quem tributamos nosso sincero agradecimento, fontes vitais desta pesquisa, trouxeram importantes contribuições nessa direção. Esperamos também que a elaboração e a divulgação desta pesquisa favoreçam o aprofundamento desse debate.

\section{Agradecimentos}

Os autores agradecem aos bolsistas de Iniciação Científica Andreza Miranda Foresti, Fábio Milani Carrara e Bernardo Guimarães e ao aluno voluntário Guilherme Mendonça Del Debbio.

\section{REFERÊNCIAS}

Badiou, A. (1995). Ética: um ensaio sobre a consciência do mal. (A. Roitman, Trad.). Rio de Janeiro: Relume-Dumará.

Brasil (2002). Parecer relativo às Diretrizes Curriculares para o Curso de Graduação em Psicologia. Ministério da 
Educação - Conselho Nacional da. Educação. Brasília, 20/2/2002. Disponível em <http://www.abepsi.org.br/ abepsi/Linha.aspx\#>. (Acesso em 02/01/2004).

Brasil (2001). Projeto de Diretrizes Curriculares Nacionais para os Cursos de Psicologia. Conselho Nacional da. Educação. Brasília. Disponível em <http://www.abepsi. org.br/abepsi/Linha.aspx\#>. (Acesso em 02/01/2004).

Brasil (2004, 19 fev.). Parecer final sobre as Diretrizes Curriculares Nacionais para os cursos de Psicologia. Relatora: Marília Ancona-Lopez. Brasília.

Ferreira Neto, J. L. (2004). A formação do psicólogo brasileiro: clínica, social e mercado. São Paulo: Escuta.

Ferreira Neto, J. L. \& Penna, L. M. D. (2004). Ética, clínica e subjetivação em Lacan e Foucault: considerações iniciais. Psico, 35(2), 207-212.

Figueiredo, L. C. (1995). Revisitando as Psicologias: da epistemologia à ética nas práticas e discursos psicológicos. São Paulo/Petrópolis:EDUC/ Vozes.

Foucault, M. (1984). História da sexualidade 2: o uso dos prazeres. (M. T. da C. Albuquerque, Trad.). Rio de Janeiro: Graal.

Japiassu, H. \& Marcondes, D. (1990). Dicionário básico de Filosofia. Rio de Janeiro: Jorge Zahar.
Lacan, J. (1988). O Seminário, Livro 7: a ética da psicanálise (1959-1960). (A. Quinet, Trad.). Rio de Janeiro: Zahar.

Pelbart, P. P. (1992). Ecologia do invisível. Pulsional, V(41), 5-13.

Penna, L. M. D. (2003). Psicanálise e Universidade: há transmissão sem clínica? Belo Horizonte: Autêntica.

Rajchman, J. (1993). Eros e verdade: Lacan, Foucault e a questão da ética. Rio de Janeiro: Jorge Zahar.

Rolnik, S. (1995). Subjetividade, ética e cultura nas práticas clínicas. Cadernos de Subjetividade, 2, 315-313.

Silva, T. T. (2002, $2^{\mathrm{a}}$ ed.). Documentos de identidade: uma introdução às teorias do currículo. Belo Horizonte: Autêntica.

Turato, E. R. (2003). Tratado da metodologia clínicoqualitativa. Petrópolis: Vozes.

Zimerman, D. E. \& Osorio, L. C. (Orgs.), (1997). Como trabalhamos com grupos. Porto Alegre: Artes Médicas.

Recebido em 28/06/2005 Aceito em 24/04/2006

Endereço para correspondência: João Leite Ferreira Neto. Rua: Planetóides 271/102, Santa Lúcia, CEP 30360-440, Belo Horizonte-MG. E-mail: jleite.bhe@terra.com.br 